\title{
Projected impact of biosimilar substitution policies on drug use and costs in Ontario, Canada: a cross-sectional time series analysis
}

\author{
Tara Gomes MHSc PhD, Daniel McCormack MSc, Sophie A. Kitchen MSc, J. Michael Paterson MSc, \\ Muhammad M. Mamdani PharmD MPH, Laurie Proulx BCom, Lorraine Bayliss ME, \\ Mina Tadrous PharmD PhD
}

Abstract

Background: Several Canadian provinces have introduced reimbursement policies mandating substitution of innovator biologics with lower-cost biosimilars. We estimated the number of patients affected and cost implications if such policy changes were to be implemented in Ontario, Canada.

Methods: We conducted a cross-sectional time series analysis of Ontarians dispensed publicly funded biologics indicated for inflammatory diseases (rheumatic conditions, inflammatory bowel disease: infliximab, etanercept, adalimumab) between January 2018 and December 2019, and forecasted trends to Dec. 31, 2020. The primary source of data was pharmacy claims data for all biologics reimbursed by the public drug program. We modelled the number of patients affected and government expenditures (in nominal Canadian dollars) of several biosimilar policy options, including mandatory nonmedical biosimilar substitution, substitution in new users, introduction of a biosimilar for adalimumab, and price negotiations. In a secondary analysis, we included insulin glargine.

Results: In 2018, 14089 individuals were prescribed a publicly funded biologic for inflammatory diseases. A mandatory nonmedical biosimilar substitution would potentially have affected 7209 patients and saved $\$ 238.6$ million from 2018 to 2020 . A new-user substitution would have affected 757 patients and saved $\$ 34.2$ million. If an adalimumab biosimilar were to become available, 12928 patients would be affected by a mandatory nonmedical substitution and the 3-year savings would increase to $\$ 645.9$ million (all biosimilars priced at $25 \%$ of innovator biologics). Finally, an expanded nonmedical substitution policy including insulin glargine would affect 115895 patients and save \$288.7 million (not including adalimumab).

Interpretation: Policies designed to curb rising costs of biologics can have substantially different effects on patients and government expenditures. Such analyses warrant careful consideration of the balance between cost savings and effects on patients.

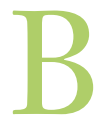

iologic drugs have improved outcomes for individuals across a range of chronic medical conditions, including diabetes and rheumatic and gastrointestinal diseases. ${ }^{1,2}$ However, unlike conventional small-molecule pharmaceuticals, biologics are derived from living organisms, are structurally more complex, and have substantially higher costs. ${ }^{1}$ In 2018 , biologics represented only $1.5 \%$ of Canadian public drug plan claims, but accounted for $27.3 \%$ of public drug costs. ${ }^{3}$ In addition to their generally higher list prices, utilization of biologics has grown substantially in the past decade. In Ontario, the total number of people taking biologics increased by $462 \%$ between 2010 and 2019, and total annual spending on these products was anticipated to reach $\$ 1.4$ billion by $2021 .^{4}$ Although biologics are improving outcomes for patients, their increasing use and high costs threaten the financial sustainability of public drug programs.
The recent expiration of patents for some biologic drugs has created opportunities for the approval of new, lower-cost "biosimilars" - biologic medicines that are highly similar to an existing innovator biologic drug, with no clinically meaningful

Competing interests: Muhammad Mamdani reports receiving honoraria from Neurocrine Biosciences, and reports being a one-time advisory board member for Roche. Laurie Proulx reports membershp of the executive of the Canadian Arthritis Patient Alliance. Tara Gomes reports receiving a grant from the Ontario Ministry of Health. No other competing interests were declared.

This article has been peer reviewed.

Correspondence to: Tara Gomes, tara.gomes@unityhealth.to CMAJ Open 2021 November 23. DOI:10.9778/cmajo.20210091 
differences in efficacy, safety or immunogenicity., In 2010, Health Canada released a regulatory framework outlining the approval process for biosimilars. ${ }^{5}$ By building on the foundation of research and development already established by innovator biologics, biosimilars offer an opportunity for substantial cost savings for public and private drug plans. ${ }^{6,7}$ The first biosimilar was marketed more than a decade ago, but uptake of biosimilars has been modest in Canada relative to other Organisation for Economic Co-operation and Development countries. ${ }^{8,9}$ Consequently, Canadian public and private drug plans have begun to implement policies aimed at expanding the use of biosimilars.

In 2019, the Canadian provincial governments of British Columbia (BC) and Alberta announced policies mandating nonmedical substitution with biosimilars among people with rheumatic conditions and inflammatory bowel disease (IBD). ${ }^{7,10}$ It is estimated that these polices will save the BC and Alberta governments nearly $\$ 100$ million each over the first 3 years of implementation. ${ }^{7,11}$ Despite these anticipated cost savings, concerns have been raised regarding potential destabilization of well-managed disease when medications are switched. ${ }^{12,13}$

The objective of this study was to estimate the number of patients potentially affected by different biosimilar policy options and the cost implications of these policies in Ontario.

\section{Methods}

\section{Design, setting and study population}

We conducted a cross-sectional time series analysis of all Ontarians dispensed a publicly funded prescription for infliximab, etanercept or adalimumab, to manage rheumatic conditions (i.e., rheumatoid arthritis, juvenile idiopathic arthritis, ankylosing spondylitis, psoriatic arthritis, and severe plaque psoriasis) or IBD (i.e., ulcerative colitis, Crohn disease) between Jan. 1, 2018, and Dec. 31, 2019. We analyzed data by month and projected forward to forecast utilization up to Dec. 31, 2020.

Three people with lived experience of using biologics participated on the study team. Their engagement included meetings throughout the project, input on the study design, interpretation of results and manuscript content.

\section{Data sources}

We used the IQVIA Drug Information File to identify relevant drug identification numbers for biologics and to categorize biologics into innovators and biosimilars, and the Ontario Drug Benefit (ODB) Program database to capture prescriptions for biologics reimbursed by the public drug program. In Ontario, individuals are eligible for ODB if they are older than 65 years, reside in a long-term care home, receive income or disability support, or have drug costs that are high relative to their income. Prescription cost data in the ODB Program database include the total amount paid by the government, and copayments and deductibles paid by the patient.

We excluded individuals who newly received public coverage for biologics during the extended Ontario Health
Insurance Program (OHIP+) drug program (which temporarily covered all children and youth) on Jan. 1, 2018, but subsequently appeared to lose coverage after changes to the program on Apr. 1, 2019, so as to ensure projected costs reflected the current OHIP+ program. We used the OHIP Registered Persons Database to determine the age and sex of individuals included in the study.

The data sets we used have been shown to be of high quality (Appendix 1, eTable 1, available at www.cmajopen.ca/ content/9/4/E1055/suppl/DC1), ${ }^{14}$ and were linked using unique encoded identifiers and analyzed at ICES.

\section{Policy definitions and cost adjustments}

We calculated total monthly costs for study biologics (infliximab, etanercept and adalimumab) in nominal Canadian dollars. This was calculated as the sum of the total paid by the Ontario Ministry of Health (i.e., the sum of the drug ingredient cost, compounding fee [if applicable], pharmacy markup and dispensing fee) and the copayments and deductibles paid by the patient. We adjusted these costs according to 2 potential reimbursement policy options, and 3 pricing considerations.

\section{Reimbursement policy options}

We considered 2 policy options that are aligned with those introduced elsewhere and that were found to be feasible and applicable within the Ontario public drug program..$^{7,10,15}$ Specifically, these were a mandatory nonmedical substitution, whereby any patient receiving an innovator biologic has therapy substituted with the relevant biosimilar; and an enforced biosimilar requirement among new users of biologics only.

We modelled the mandatory nonmedical substitution by identifying all innovator biologic prescriptions dispensed each month and multiplying the medication ingredient costs by an adjustment factor (calculated as the median price paid by the Ontario Ministry of Health for biosimilar prescriptions reimbursed over the study period as a proportion of the cost reimbursed for the innovator biologic) to reduce the cost to that of the relevant biosimilar (Table 1). We then calculated the new pharmacy markup $(6 \%$ for claims above $\$ 1000$ and $8 \%$ for claims below $\$ 1000$, aligning with current markup policies) and added it to the adjusted costs, along with dispensing fees.

In contrast, when modelling the biosimilar requirement among new users only, we applied these adjusted costs only to people newly starting an innovator biologic in the month of interest, or to people who had previously started an innovator biologic during our study period. This will accumulate cost implications over time as we assumed that new users from earlier months continued using the biosimilar in future months.

\section{Pricing and policy expansion considerations}

We combined the 2 policy options above with 3 policy considerations. First, we modelled the impact of the introduction of a biosimilar for adalimumab (which did not have a marketed biosimilar in Canada during the study period). In this 
Table 1: Adjustment factors for biologic prices

\begin{tabular}{|lcccc|}
\hline Biologic & $\begin{array}{c}\text { Primary analysis: } \\
\text { adjustment factor, } \%\end{array}$ & $\begin{array}{c}\text { Policy consideration \#1: } \\
\text { include insulin } \\
\text { glargine, } \%\end{array}$ & $\begin{array}{c}\text { Policy consideration \#2: } \\
\text { include biosimilar for } \\
\text { adalimumab, } \%\end{array}$ & $\begin{array}{c}\text { Policy consideration \#3: } \\
\text { negotiated price } \\
\text { reductions below } \\
\text { threshold, } \%\end{array}$ \\
\hline Etanercept & 62.0 & 62.8 & 62.8 & 75,50 \\
\hline Infliximab & 53.2 & 53.2 & 53.2 & 75,50 \\
\hline Adalimumab & $\mathrm{NA}$ & $\mathrm{NA}$ & 60.0 & 75,50 \\
\hline Insulin glargine & $\mathrm{NA}$ & 75.0 & $\mathrm{NA}$ & $\mathrm{NA}$ \\
\hline Note: NA = not applicable. & & & & \\
\hline
\end{tabular}

analysis, we adjusted the price of the innovator to align with the price of the newly approved adalimumab biosimilar (60\%; Table 1). Second, we modelled the implications of price negotiations across all biologics for IBD and rheumatic conditions, setting biosimilar cost thresholds at $25 \%$ and $50 \%$ of the innovator price. Finally, we modelled the impact of adding insulin glargine, a long-acting insulin, to the list of currently available innovator biologics with an assumed biosimilar cost of $75 \%$ of the innovator cost. These policy considerations were informed by previous policies introduced in $\mathrm{BC}$ (which include insulin and adalimumab) and Alberta (which includes adalimumab), ${ }^{7,10}$ and through discussions with managers of public drug plans across Canada to establish estimates of cost thresholds.

\section{Statistical analysis}

We summarized patient- and prescription-level characteristics for all biologics indicated for rheumatic conditions or IBD dispensed in calendar year 2018 overall and stratified by biologic type. In the time series analysis, we modelled and forecasted monthly costs of biologics based on current trends (calendar years 2018/19), under each of the policy options and considerations up to Dec. 31, 2020, using a Holt-Winters exponential smoothing model with the additive method, selected to provide the optimal model fit. ${ }^{16,17}$ To estimate the 3 -year cost implications of each policy option, we summed the adjusted actual and forecasted costs from January 2018 to December 2020 in each model. We estimated the number of individuals affected by each policy option according to the real-world prescribing patterns in 2018. In 2 sensitivity analyses, we expanded our cohort definition to include Ontarians dispensed insulin glargine over the same study period, to align with similar policies introduced in BC, and replicated our primary analysis considering only costs to the public payer.

Analyses were conducted at ICES using SAS Enterprise Guide, version 7.1 (SAS Institute, Inc. Cary, NC) and used a type 1 error rate of 0.05 to determine statistical significance.

\section{Ethics approval}

The use of data in this project was authorized under section 45 of Ontario's Personal Health Information Protection Act, which does not require review by a Research Ethics Board.

\section{Results}

In 2018, 14089 individuals received a publicly funded biologic indicated for rheumatic conditions or IBD (Table 2). Adalimumab was prescribed most frequently $(n=5782$, $41.0 \%)$, followed by infliximab $(n=4558,32.4 \%)$ and etanercept $(n=3872,27.5 \%)$. Overall, $54.3 \%(n=7656)$ of users of biologics were women and $61.8 \%(n=8703)$ were younger than 65 years, although these patterns differed by drug. For example, $63.4 \%(n=2454)$ of users of etanercept were women, and $58.3 \%(n=2258)$ were older than 65 years.

Among biologics with a biosimilar available in Ontario, $84.1 \%(n=3256)$ of users of etanercept and $86.7 \%(n=3954)$ of users of infliximab were treated with an innovator. However, when we considered new use, $39.5 \%(n=305)$ of people starting etanercept and $59.8 \%(n=459)$ of those starting infliximab began on an innovator.

Overall, the cost of biologics in 2018 was \$280782 091, and the average cost of biologics per person was $\$ 19929$, ranging from $\$ 16034$ per person treated with etanercept to $\$ 27272$ per person treated with infliximab.

\section{Trends in monthly costs}

The monthly costs of biologics for rheumatic conditions and IBD increased over our study period, rising from $\$ 21883713$ in January 2018 to $\$ 26331208$ in December 2019 (Figure 1). Monthly costs were forecasted to reach \$28246752 (95\% confidence interval [CI] \$26984908 to $\$ 29508595)$ by December 2020 if current trends continued. In the sensitivity analysis that considered only public payer costs, monthly costs and patterns were similar over time (rise from $\$ 21682705$ to $\$ 25678079$ from January 2018 to December 2019). Assuming current reimbursement policies for biologics indicated for IBD and rheumatic conditions remained the same in Ontario, we anticipated that these medications would cost a total of $\$ 925266759$ from 2018 to 2020.

\section{Policy impact}

The impact of policies on the number of patients affected and the resulting cost savings varied considerably depending on the policy selected (Table 3 and Figure 2). The fewest patients 
Table 2: Characteristics of biologics use among people with rheumatic or gastrointestinal conditions, 2018

\begin{tabular}{|c|c|c|c|c|}
\hline \multirow[b]{2}{*}{ Characteristic } & \multicolumn{4}{|c|}{ No. $(\%)^{\star}$ of people prescribed a biologic } \\
\hline & $\begin{array}{c}\text { Any biologic } \\
n=14089\end{array}$ & $\begin{array}{c}\text { Etanercept } \\
n=3872\end{array}$ & $\begin{array}{c}\text { Adalimumab } \\
n=5782\end{array}$ & $\begin{array}{c}\text { Infliximab } \\
n=4558\end{array}$ \\
\hline \multicolumn{5}{|l|}{ Sex } \\
\hline Male & $6433(45.7)$ & $1418(36.6)$ & $2664(46.1)$ & $2405(52.8)$ \\
\hline Female & $7656(54.3)$ & $2454(63.4)$ & $3118(53.9)$ & $2153(47.2)$ \\
\hline \multicolumn{5}{|l|}{ Age, yr } \\
\hline$<18$ & $441(3.1)$ & $51(1.3)$ & $179(3.1)$ & $224(4.9)$ \\
\hline $18-44$ & $4310(30.6)$ & $456(11.8)$ & $1838(31.8)$ & $2049(45.0)$ \\
\hline $45-64$ & $3952(28.1)$ & $1107(28.6)$ & $1682(29.1)$ & $1195(26.2)$ \\
\hline$\geq 65$ & $5386(38.2)$ & $2258(58.3)$ & $2083(36.0)$ & $1090(23.9)$ \\
\hline Patients treated with any innovator biologics & $12928(91.8)$ & $3256(84.1)$ & $5782(100)$ & $3954(86.7)$ \\
\hline \multicolumn{5}{|l|}{ New users } \\
\hline Biologics & 3219 & 773 & 1708 & 767 \\
\hline Innovator biologics & $2924(90.8)$ & $305(39.5)$ & $1708(100)$ & $459(59.8)$ \\
\hline \multicolumn{5}{|l|}{ Prescriptions dispensed } \\
\hline Biologics & 98070 & 27920 & 41582 & 28568 \\
\hline Innovator biologics & $91261(93.1)$ & $24270(86.9)$ & $41582(100)$ & $25409(88.9)$ \\
\hline \multicolumn{5}{|l|}{ Total cost, \$ } \\
\hline Biologics & 280782091 & 62083387 & 94391665 & 124307040 \\
\hline Innovator biologics & 268348355 & 57336774 & 94391665 & 116619916 \\
\hline Average no. biologic prescriptions/person & 7.0 & 7.2 & 7.2 & 6.3 \\
\hline Average cost of biologics per person, $\$$ & 19929 & 16034 & 16325 & 27272 \\
\hline
\end{tabular}

were affected if only new users of etanercept and infliximab were required to use a biosimilar ( $n=757$ in 2018). This policy also led to the smallest percentage reduction in costs between 2018 and 2020 (3.7\% reduction; $\$ 34236463$ in savings over 3 years). We estimated that a policy mandating nonmedical substitution for all users of etanercept and infliximab innovators would affect 7209 patients upon implementation, and save $\$ 238589858$ over 3 years (25.8\% cost reduction). In policies including insulin glargine, the number of patients affected would be considerably higher, reaching 115895 in 2018 for mandatory nonmedical substitution, and 23680 for a new user substitution. The percentage price reductions are similar for these policies as for those focusing on etanercept and infliximab; however, the absolute cost savings over 3 years are higher (\$288733259 and \$45341592 for mandatory nonmedical substitution and new user substitution, respectively).

The impact of policies on costs varied depending on the availability of an adalimumab biosimilar and the degree of price negotiations, with the policy leading to the largest 3 -year cost savings being a mandatory nonmedical substitution of 12928 users of etanercept, infliximab and adalimumab innovators where prices are negotiated to $25 \%$ of the innovator cost $(69.8 \%$ reduction; $\$ 645879599$ over 3 years; Table 3$)$.

\section{Interpretation}

In this population-based study, we found that policies designed to increase uptake of biosimilars differed substantially in their impact on patients and government costs. In 2018, infliximab, etanercept and adalimumab cost the Ontario public drug program $\$ 280.8$ million, $95.6 \%$ of which was attributed to innovator biologics. Depending on the policy implemented and negotiated biosimilar prices, we estimated the potential 3-year (2018-2020) cost savings of biosimilar reimbursement policies to range between $\$ 34.2$ million (3.7\% savings; enforced new user substitution for etanercept and infliximab only) and \$645.9 million (69.8\% savings; mandatory nonmedical substitution for etanercept, infliximab and adalimumab, each priced at $25 \%$ of innovator biologics). Similarly, the number of patients affected by the policies ranged from 757 to 115895 annually, depending on the policy selected.

Overall, the considerable cost savings and number of patients affected by the biosimilar policy changes examined in this study are within the range of estimates found in other jurisdictions, both nationally and internationally. In Canada, $\mathrm{BC}$ and Alberta estimated their biosimilar policies would affect between 40 and 60 patients per 10000 population and save about $\$ 1500$ and $\$ 3000$ per patient, respectively., ${ }^{7,11}$ 


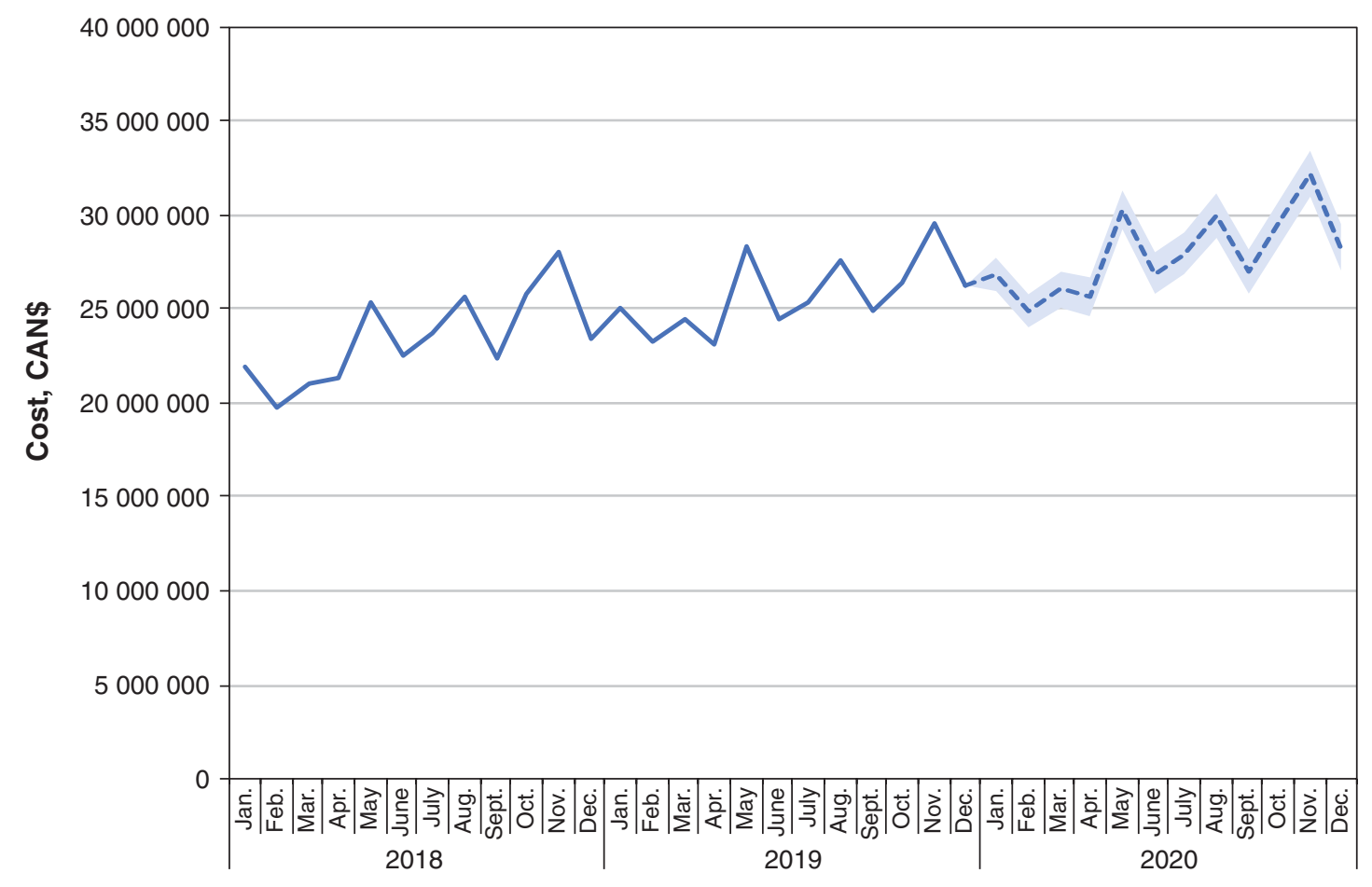

Year and month

Figure 1: Forecasted trends in monthly biologics costs over time if current trends continue. Actual data are presented with a solid line from January 2018 to December 2019, with projected estimates presented with a dashed line for calendar year 2020. The shaded area indicates the $95 \%$ confidence intervals for these estimates.

Our analysis found that a nonmedical substitution policy for etanercept, infliximab and insulin glargine (which is most similar to BC and Alberta's policies) would affect about 80 patients per 10000 population and save nearly $\$ 900$ per patient in Ontario.

Although there have been many international studies examining the effect of biosimilars on the budget of public drug programs, primarily in Europe, many of these analyses are not directly comparable with this study owing to the variability of policies, product availability, populations studied and research methodology..$^{18} \mathrm{~A}$ recent systematic review compiled 15 international studies and found that nonmedical substitution of biosimilars for etanercept, infliximab or adalimumab resulted in a wide range of cost savings (about $€ 7$ to $€ 13739$ per patient per year). ${ }^{19}$ The variation between provincial estimates in Canada and international comparisons is likely a result of differences in the medications included in the biosimilar policies, ${ }^{7}$ the prevalence of associated diseases, ${ }^{20-22}$ and drug coverage before policy implementation. ${ }^{23}$ However, this international research suggests that policies requiring nonmedical switches or automatic substitutions with biosimilars generally lead to rapid shifts in dispensing patterns and large cost reductions for public payers, but potentially increased costs related to health services utilization. ${ }^{15,19,24}$
Although cost considerations can be an important driver of policy change, the way in which biologics are dispensed introduces an additional layer of complexity for optimal reimbursement policy. For example, although biosimilars have been shown to be effective and safe, ${ }^{25}$ some clinicians are concerned that substituting treatment for patients already stable on one therapy could cause anxiety among those who are experiencing benefit from their current medication and could destabilize their condition. This could both affect patient outcomes and incur costs to the health care system. This concern appears to be greater for patients with IBD, owing to uncertainty about destabilization of their condition and the more limited number of biologic options. ${ }^{13,26}$

A unique aspect of biologic provision is that some patient care and medication administration costs (e.g., infusion clinics, laboratory tests, patient support nurses) are funded by biologic drug manufacturers. In addition, drug manufacturers often assist patients with their copayments. Therefore, any policies introducing mandatory changes in therapy need to allow for scaling-up of these services for the corresponding biosimilars. This includes anticipating funding to provide clinical support to patients when undergoing a change in therapy, and identifying potential implications for the patient copayments and financial support often provided by innovator biologics manufacturers. 


\begin{tabular}{|c|c|c|c|c|c|c|}
\hline Cost implications & $\begin{array}{l}\text { No. patients } \\
\text { affected } \\
(2018) \dagger\end{array}$ & $\begin{array}{l}\text { Savings } \\
2018, \$\end{array}$ & $\begin{array}{l}\text { Savings } \\
2019, \$\end{array}$ & $\begin{array}{l}\text { Savings } \\
2020, \$\end{array}$ & $\begin{array}{l}\text { Total 3-year } \\
\text { savings, } \$\end{array}$ & $\begin{array}{c}\% \text { Reduction } \\
\text { costs }\end{array}$ \\
\hline \multicolumn{7}{|l|}{ Etanercept and infliximab only } \\
\hline $\begin{array}{l}\text { Everyone switches to currently } \\
\text { available biosimilar }\end{array}$ & 7209 & 75711829 & 79753211 & 83124819 & 238589858 & -25.8 \\
\hline $\begin{array}{l}\text { Only new users required to use } \\
\text { currently available biosimilar }\end{array}$ & 757 & 6386595 & 11810257 & 16039611 & 34236463 & -3.7 \\
\hline \multicolumn{7}{|l|}{ Including adalimumab biosimilart } \\
\hline $\begin{array}{l}\text { Everyone switches to biosimilar } \\
\text { (adalimumab @ 60\% innovator cost) }\end{array}$ & 12928 & 112774144 & 122160470 & 130684224 & 365618838 & -39.5 \\
\hline $\begin{array}{l}\text { Only new users are required to use } \\
\text { biosimilar (adalimumab @ } 60 \% \\
\text { innovator cost) }\end{array}$ & 2443 & 14456007 & 28967204 & 42164844 & 85588055 & -9.3 \\
\hline \multicolumn{7}{|c|}{ New cost thresholds for all biologics (etanercept, infliximab and adalimumab) $\dagger$} \\
\hline $\begin{array}{l}\text { Everyone switches to biosimilar } \\
\text { (all biologics @ } 50 \% \text { innovator cost) }\end{array}$ & 12928 & 133002041 & 143605795 & 153276509 & 429884345 & -46.5 \\
\hline $\begin{array}{l}\text { Only new users are required to use } \\
\text { biosimilar (all biologics @ } 50 \% \\
\text { innovator cost) }\end{array}$ & 2443 & 17273891 & 34758620 & 50939083 & 102971594 & -11.1 \\
\hline $\begin{array}{l}\text { Everyone switches to biosimilar } \\
\text { (all biologics @ 25\% innovator cost) }\end{array}$ & 12928 & 199861495 & 215784478 & 230233627 & 645879599 & -69.8 \\
\hline $\begin{array}{l}\text { Only new users are required to use } \\
\text { biosimilar (all biologics @ } 25 \% \\
\text { innovator cost) }\end{array}$ & 2443 & 25965104 & 52250289 & 76614092 & 154829485 & -16.7 \\
\hline \multicolumn{7}{|l|}{ Etanercept, infliximab and insulin glargine† } \\
\hline $\begin{array}{l}\text { Everyone switches to currently } \\
\text { available biosimilar }\end{array}$ & 115895 & 94857347 & 96465505 & 97410407 & 288733259 & -25.3 \\
\hline $\begin{array}{l}\text { Only new users required to use } \\
\text { currently available biosimilar }\end{array}$ & 23680 & 8541779 & 15386458 & 21413355 & 45341592 & -4.0 \\
\hline
\end{tabular}

Given the limited real-world evidence regarding the safety of mandatory nonmedical biosimilar substitution, particularly for patients with IBD, jurisdictions introducing these policies should monitor patient outcomes, including clinical consequences and costs, out-of-pocket expenses and quality of life.

\section{Limitations}

Although we used real-world data on publicly funded biologics to estimate the potential impacts of different biosimilar policies in Ontario, several limitations to this study merit discussion. In the absence of an available biosimilar for adalimumab, it would be possible that biologics prescribing could be channelled toward this product if a mandatory nonmedical substitution policy was introduced. Although we are unable to estimate the cost implications of such a change in clinical practice in our models, data after a similar policy change in BC suggest this did not occur..$^{27}$ Furthermore, in February 2021, adalimumab biosimilars became available on the Canadian market and were added to the Ontario public drug formulary in March 2021 at $60 \%$ of the price of the innovator. Therefore, all available innovator biologics now have a biosimilar available, thus reducing the potential for channelling.

The Ontario Public Drug Programs already has a policy requiring biosimilars among new users of infliximab or etanercept; however, when patients are started on medications in hospital or they receive their first dose at low cost from the manufacturer, these policies are circumvented. Therefore, although new-user policies are potentially more acceptable to patients, they may have limited effectiveness for public payers. As our model indicates, considerable additional savings could be achieved if the intended new-user biosimilar policy was fully enforceable, although it is not known whether this can be achieved when other factors remain outside government control.

Our study is limited to estimating the cost implications of biosimilar policy changes applied to the public drug program in Ontario, and therefore does not provide estimates of cost implications if similar policies were introduced by 


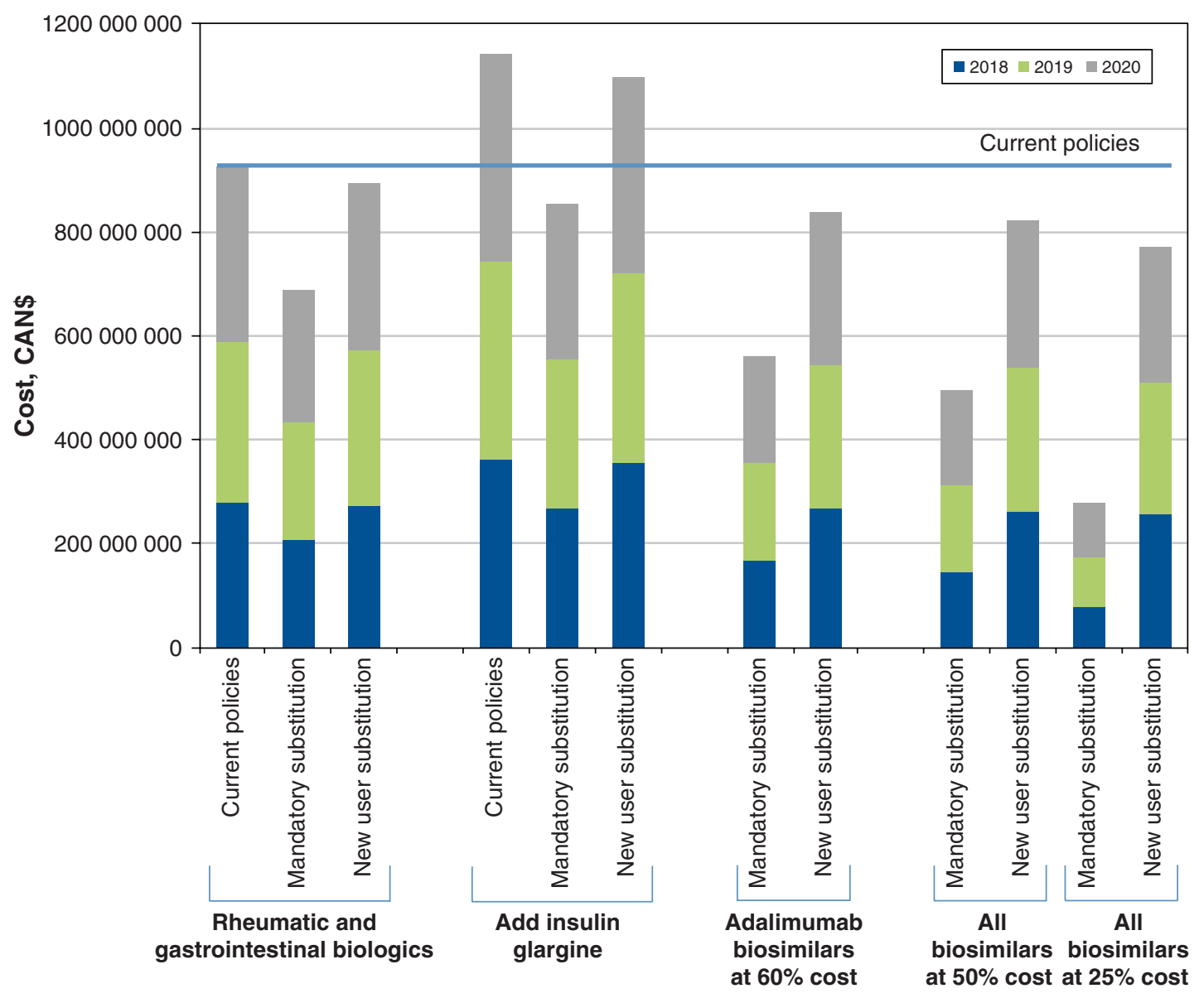

Figure 2: Expected 3-year costs of biologics after modelling different policy scenarios, 2018-2020.

private drug insurers who typically provide coverage to younger (i.e., < $65 \mathrm{yr}$ ) populations. However, younger patients with high drug costs are increasingly accessing Ontario's catastrophic drug program (Trillium), which means that drug policy decisions made by public drug programs will affect them. ${ }^{28}$

We were unable to incorporate negotiated price reductions (rebates) already implemented in Ontario as these are confidential; the cost savings reported here therefore used the list price of the medications. Hence, we determined 2 potential thresholds for price reductions $(25 \%$ and $50 \%$ of innovator cost) through consultation with policy-makers across Canada. Although achieving price reductions as low as $25 \%$ of the innovator cost may be unlikely, this provides a wide array of cost implications that can inform future price negotiations by public drug programs in Canada.

\section{Conclusion}

In this large population-based study, we found that policies designed to address the rising costs of biologics differ substantially in their impact on patients and cost savings. Given the complexity of the supply chain for these medications, including the role of manufacturers in drug provision, careful consideration of the balance between cost savings and patient access is warranted. Plans for enacting specific initiatives should consider forming partnerships with key stakeholder groups to ensure that patient and provider perspectives are incorporated.

\section{References}

1. Biosimilar biologic drugs in Canada: fact sheet. Ottawa: Health Canada; 2019.

2. ICMRA statement about confidence in biosimilar products (for healthcare professionals). San Diego (CA): International Coalition of Medicines Regulatory Authorities (ICMRA); 2019.

3. Biologics in Canada: part 1: market trends. Ottawa: Patented Medicine Prices Review Board; 2020.

4. Tadrous M, McCormack D, Martins D, et al. Current and prospective utilization of innovator biologics and biosimilars in Ontario. Toronto: Ontario Drug Policy Research Network; 2020.

5. Guidance document: information and submission requirements for biosimilar biologic drugs. Ottawa: Health Canada; 2016.

6. Kabir ER, Moreino SS, Sharif Siam MK. The breakthrough of biosimilars: a twist in the narrative of biological therapy. Biomolecules 2019;9:410.

7. Biosimilars initiative for patients. Vancouver: Government of British Columbia; 2019. Available: https://www2.gov.bc.ca/gov/content/health/health-drug-coverage /pharmacare-for-bc-residents/what-we-cover/drug-coverage/biosimilars-initiative -patients (accessed 2020 May 14). 
8. Biosimilars in Canada: current environment and future opportunity. Ottawa: Patented Medicine Prices Review Board; 2019.

9. Biologics in Canada: part 2: biosimilar savings. Ottawa: Patented Medicine Prices Review Board; 2020.

10. Biosimilar drugs. Alberta: Government of Alberta; 2020. Available: https:// www.alberta.ca/biosimilar-drugs.aspx (accessed 2020 May 14).

11. Biosimilar initiative. Edmonton: Alberta Health; 2020.

12. Kaplan GG, Ma C, Seow $\mathrm{CH}$, et al. The argument against a biosimilar switch policy for infliximab in patients with inflammatory bowel disease living in Alberta. 7 Can Assoc Gastroenterol 2020;3:234-42.

13. Crain J, Mawani M, Lee K, et al. Patient and health care provider input: nonmedical biosimilar switch policy for patients with inflammatory bowel disease. Toronto: Crohn's and Colitis Canada; 2019.

14. Levy AR, O'Brien BJ, Sellors C, et al. Coding accuracy of administrative drug claims in the Ontario Drug Benefit database. Can 7 Clin Pharmacol 2003;10:67-71.

15. Jensen TB, Bartels D, Saedder EA, et al. The Danish model for the quick and safe implementation of infliximab and etanercept biosimilars. Eur 7 Clin Pharmacol 2020;76:35-40.

16. Kalekar PS. Time series forecasting using Holt-Winters exponential smoothing. Mumbai: Kanwal Rekhi School of Information Technology; 2004:1-13.

17. Fuertes EI, Henry B, Marra F, et al. Trends in antibiotic utilization in Vancouver associated with a community education program on antibiotic use. Can 7 Public Health 2010;101:304-8.

18. Moorkens E, Vulto A, Huys I, et al. Policies for biosimilar uptake in Europe: an overview. PLoS One 2017;12:e190147.

19. Liu $Y$, Yang $M$, Garg V, et al. Economic impact of non-medical switching from originator biologics to biosimilars: a systematic literature review. Adv Ther 2019;36:1851-77.

20. Broten L, Aviña-Zubieta JA, Lacaille D, et al. Systemic autoimmune rheumatic disease prevalence in canada: updated analyses across 7 provinces. 7 Rheumatol 2014;41:673-9.

21. Kaplan GG, Bernstein CN, Coward S, et al. The impact of inflammatory bowel disease in Canada 2018: Epidemiology. 7 Can Assoc Gastroenterol 2019;2 (Suppl 1):S1-S5.

22. Health Fact Sheets: Diabetes, 2017. Ottawa: Statistics Canada; 2018.

23. Campbell DJ, Manns BJ, Soril LJ, et al. Comparison of Canadian public medication insurance plans and the impact on out-of-pocket costs. CMAf Open 2017;5:E808.

24. Jensen TB, Kim SC, Jimenez-Solem E, et al. Shift from adalimumab originator to biosimilars in Denmark. FAMA Intern Med 2020;180:902-3.

25. Barbier L, Ebbers HC, Declerck P, et al. The efficacy, safety, and immunogenicity of switching between reference biopharmaceuticals and biosimilars: a systematic review. Clin Pharm Therapeut 2020;108:734-55.

26. Canadian Rheumatology Association (CRA) position statement on biosimilars. Mississauga (ON): Canadian Rheumatology Association; 2019.

27. Crosby M, Tadrous M, Gomes T. Potential cost implications of mandatory non-medical switching policies for biologics for rheumatic conditions and inflammatory bowel disease in Canada. Clin Pharmacol Ther 2021;109:739-45.

28. Tadrous M, Greaves S, Martins D, et al. Catastrophic drug coverage: utilization insights from the Ontario Trillium Drug Program. CMAF Open 2018;6:E132-8.
Affiliations: Unity Health Toronto and the Li Ka Shing Knowledge Institute (Gomes, Kitchen, Mamdani), St. Michael's Hospital; ICES (Gomes, McCormack, Paterson, Mamdani, Tadrous); Canada; Institute for Health Policy, Management, and Evaluation (Gomes, Paterson, Mamdani), and the Leslie Dan Faculty of Pharmacy (Gomes, Mamdani, Tadrous) at the University of Toronto, Toronto, Ont.; Department of Family Medicine (Paterson), McMaster University, Hamilton, Ont.; Women's College Hospital (Tadrous), Ontario Drug Policy Research Network (Gomes, McCormack, Kitchen, Paterson, Mamdani, Proulx, Bayliss, Tadrous), Toronto, Ont.

Contributors: All of the authors contributed to the conception and design of the work, and the acquisition and interpretation of data. Daniel McCormack, Mina Tadrous and Tara Gomes contributed to the analysis of data. Tara Gomes drafted the manuscript. All of the authors revised it critically for important intellectual content, gave final approval of the version to be published and agreed to be accountable for all aspects of the work.

Data sharing: The data set from this study is held securely in coded form at ICES. While data-sharing agreements prohibit ICES from making the data set publicly available, access may be granted to those who meet pre-specified criteria for confidential access, available at https:/www.ices.on.ca/DAS.

Funding: This study was funded by a grant from the Ontario Ministry of Health. This study was also supported by ICES, which is funded by an annual grant from the Ontario Ministry of Health and the Ministry of Long-Term Care.

Content licence: This is an Open Access article distributed in accordance with the terms of the Creative Commons Attribution (CC BY-NC-ND 4.0) licence, which permits use, distribution and reproduction in any medium, provided that the original publication is properly cited, the use is noncommercial (i.e., research or educational use), and no modifications or adaptations are made. See: https://creativecommons.org/licenses/ by-nc-nd/4.0/

Acknowledgement: The authors thank IQVIA Solutions Canada Inc. for use of its Drug Information File.

Supplemental information: For reviewer comments and the original submission of this manuscript, please see www.cmajopen.ca/content/9/4/ E1055/suppl/DC1

Disclaimer: The opinions, results and conclusions reported in this article are those of the authors and are independent from the funding sources. No endorsement by ICES or the Ontario Ministry of Health is intended or should be inferred. 